\title{
COMPLETING AND REFINING OF THE MATERIAL LIBRARY FOR FORMING SIMULATIONS
}

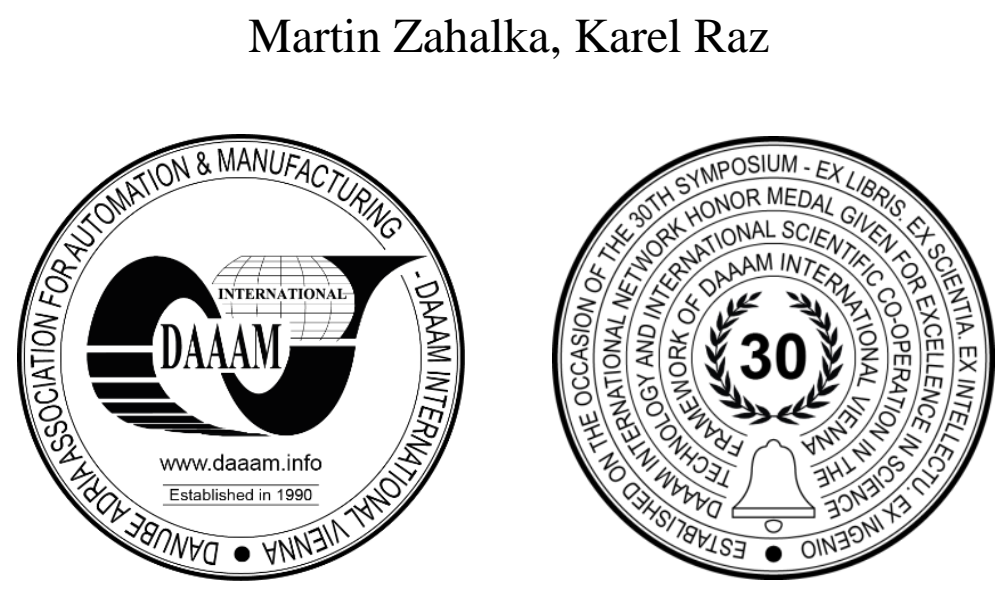

This Publication has to be referred as: Zahalka, M[artin] \& Raz, K[arel] (2019). Completing and Refining of the Material Library for Forming Simulations, Proceedings of the 30th DAAAM International Symposium, pp.0384-0389, B. Katalinic (Ed.), Published by DAAAM International, ISBN 978-3-902734-22-8, ISSN 1726-9679, Vienna, Austria DOI: $10.2507 / 30$ th.daaam.proceedings.052

\begin{abstract}
The paper deals with the software DEFORM, which is used for forming simulations at the Regional Technological Institute in University of West Bohemia in Pilsen, and with the issue of acquisition and validation of material data. Material library is an essential part of a software, but sometimes it is necessary to add individual material into the library or edit existing materials to improve their description.

The article describes the real material tests and individual parameters that should be considered during material description. Further is shown data conversion for virtual simulations in DEFORM software. At the end, the verification of material description is shown. It is done by the comparing of results given by virtual simulation and by the real forming process. The whole procedure of new material description is shown on the brass CuZn30. Material description is deeply described in this paper.
\end{abstract}

Keywords: Brass; Material library; CuZn30; metal forming; Deform

\section{Introduction}

The software DEFORM 3D is used for forming simulations at the Regional Technological Institute in University of West Bohemia in Pilsen. It can be used for simulations of forming, thermal treatment and machining. Material library is an essential part of a software, but it is not possible to involve all materials. The DEFORM 3D software is mainly focused on steels and therefore is the material library consisted mainly from these materials. Non-ferrous materials are also involved but their number is limited.

It is necessary to add individual material into the library when in is not included. Correct data are essential for each simulation. It is sometimes better to edit existing materials and improve their description. This can be done according to actual parameters of selected producer or according to the particular melting process.

It is necessary to perform the correct virtual simulation of the forming with respect to the costs minimization and the production preparation. It is possible to produce the final product (forming tool in this case) when are all simulations correct. These tools are very expensive, but it is not necessary to perform any additional manufacturing when simulations are performed correctly.

Correct boundary conditions and input data are essential for good simulations. The material definition is the key parameter for simulations of metal forming [1]. These parameters can be involved in the software for forming or is 
necessary to add them by the user. In the case of the self-produced materials, their mechanical properties do not have to match the data in the database. [2]. Final data are dependent on actual parameters of selected producer or according to the particular melting process [3].

\section{Material testing}

The performed material test is focused on the bras CuZn30. This material is produced by the rolling process as a sheet with thickness $3.78 \mathrm{~mm}$. Material data are modified with respect to the DEFORM 3D software and validation was performed.

\subsection{Measured data}

It is necessary to measure various parameters for the complex description of material properties. It is enough to perform the simple tensile test with various loading.

The range of testing parameters depends on the range during the operation (temperatures, etc.). It is not necessary to measure material data at ambient temperature when material is used for the hot forging.

The frequency of measurement is dependent on the scatter of the measured data. It is not necessary to perform testing at $125^{\circ} \mathrm{C}$, when data for $100^{\circ} \mathrm{C}$ and $150^{\circ} \mathrm{C}$ are available and strength is comparable (for example).

Required parameters for the elastic deformation: Young modulus, Poisson ratio

Parameters for the plastic deformation: dependency stress - longitudinal and transversal deformation

All parameters has to be measured with respect to the temperature and the velocity (the direction) of loading.

\subsection{Range of parameters}

Temperature $20-200{ }^{\circ} \mathrm{C}$

Velocity $150-600 \mathrm{~mm} / \mathrm{min}$

Anisotropy $0-90^{\circ}$

The initial measurement was performed in limits described above. Additional test was performed according changes in results.

\subsection{Specimen for the material testing}

The tensile test was performed for individual specimens from various areas of the sheet. This process can describe whole width of the rolled material. It is necessary to use specimens with different orientation in the sheet. This is useful for description of the anisotropy of the material [4].

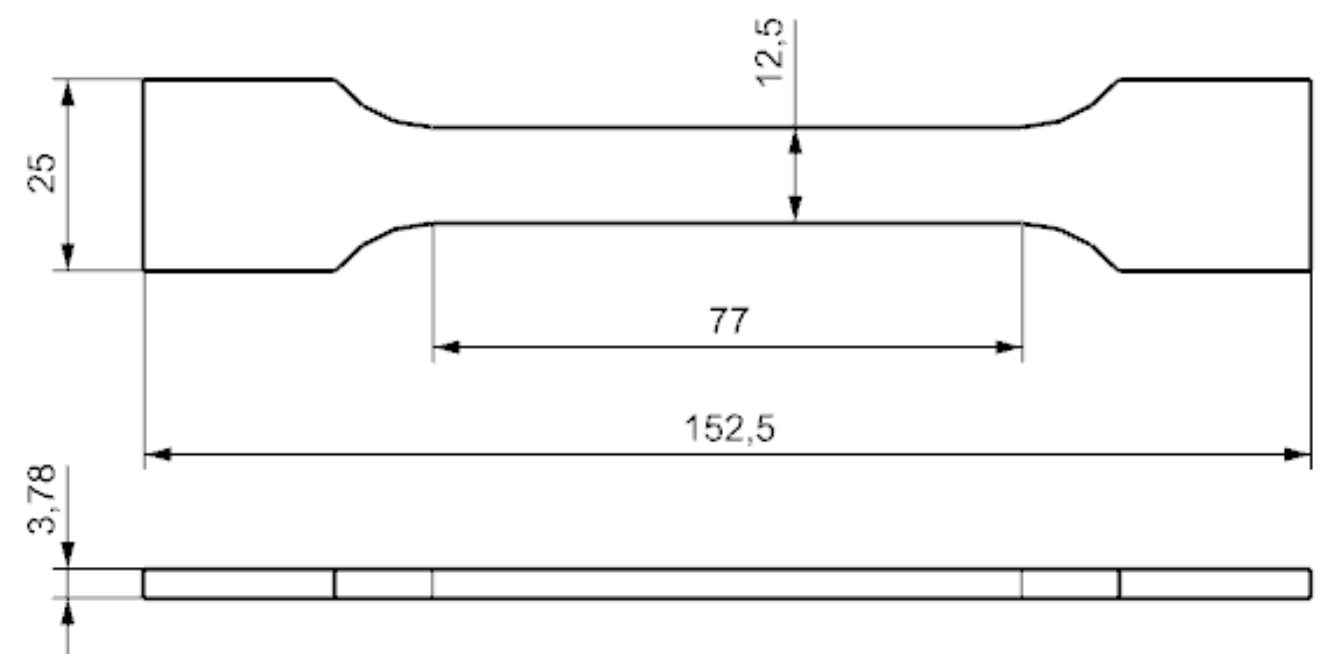

Fig. 1. Tensile test dimensions

\section{Results of tensile test measurement}

Measured values of the tensile strength are shown in the following table with respect to the temperature, to the velocity and to the direction of loading. Three individual measurements were performed of each load case. 
It is not necessary to perform other tests with different velocities, because measured results are not varying significantly.

It is obvious, that material is mainly isotropic (comparing of the strength in the transversal and longitudinal direction). It is not necessary to consider this anisotropy in the simulation $[5,6]$.

\begin{tabular}{|c|c|c|c|}
\hline $\begin{array}{c}\text { Direction of } \\
\text { specimen }\end{array}$ & Temperature $\left[{ }^{\circ} \mathrm{C}\right]$ & Velocity $[\mathrm{mm} / \mathrm{s}]$ & Stress $[\mathrm{MPa}]$ \\
\hline \multirow{3}{*}{ Longitudinal } & \multirow{2}{*}{20} & 150 & $335-337$ \\
\cline { 2 - 4 } & \multirow{2}{*}{200} & 600 & $333-336$ \\
\cline { 2 - 4 } & \multirow{2}{*}{20} & 150 & $300-309$ \\
\cline { 2 - 4 } & \multirow{2}{*}{ Transversal } & 600 & $299-302$ \\
\cline { 2 - 4 } & \multirow{2}{*}{200} & 150 & $329-331$ \\
\cline { 2 - 4 } & & 600 & $293-324$ \\
\hline
\end{tabular}

Table 1. Results of tensile tests

The influence of the temperature $\left(20-200^{\circ} \mathrm{C}\right)$ is not negligible as is shown in Table 1 . It is necessary to involve it in the material model. The maximal temperature during the considered forging process is $200^{\circ} \mathrm{C}$. The measured temperature range is therefore sufficient. The dependency between the strength of the material and the temperature is considered as linear $[7,8]$.

One individual tensile test is shown in the following graph. Results are for the longitudinal direction, temperature $20^{\circ} \mathrm{C}$ and velocity $150 \mathrm{~mm} / \mathrm{s}$. The result is an average value from three individual measurements. The stress has to be converted into the real value, which is considering thinning of the specimen.
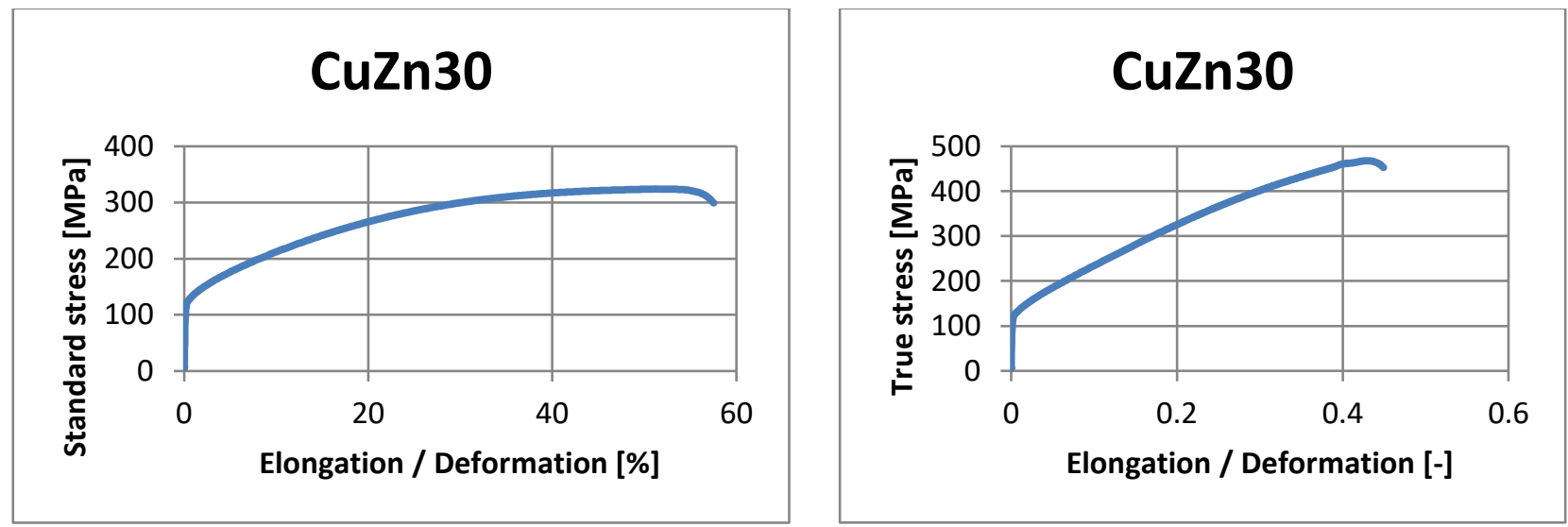

Fig. 2. Tensile test - measured stress and true stress

\section{Data conversion to Deform}

The validation of the material data was performed by the virtual simulation of the tensile test. The measured data was used it the DEFORM 3D software according the following figure.

The tensile test curve has been simplified to several linear parts, which are entered into the table. The use of more points for the area of transition from the elastic to the plastic part of tensile test is very suitable.

The tensile curves are entered individually for different speeds, temperatures and so on. The material parameters lying between the measured values are linearly or logarithmic interpolated from the nearest values. [9] 

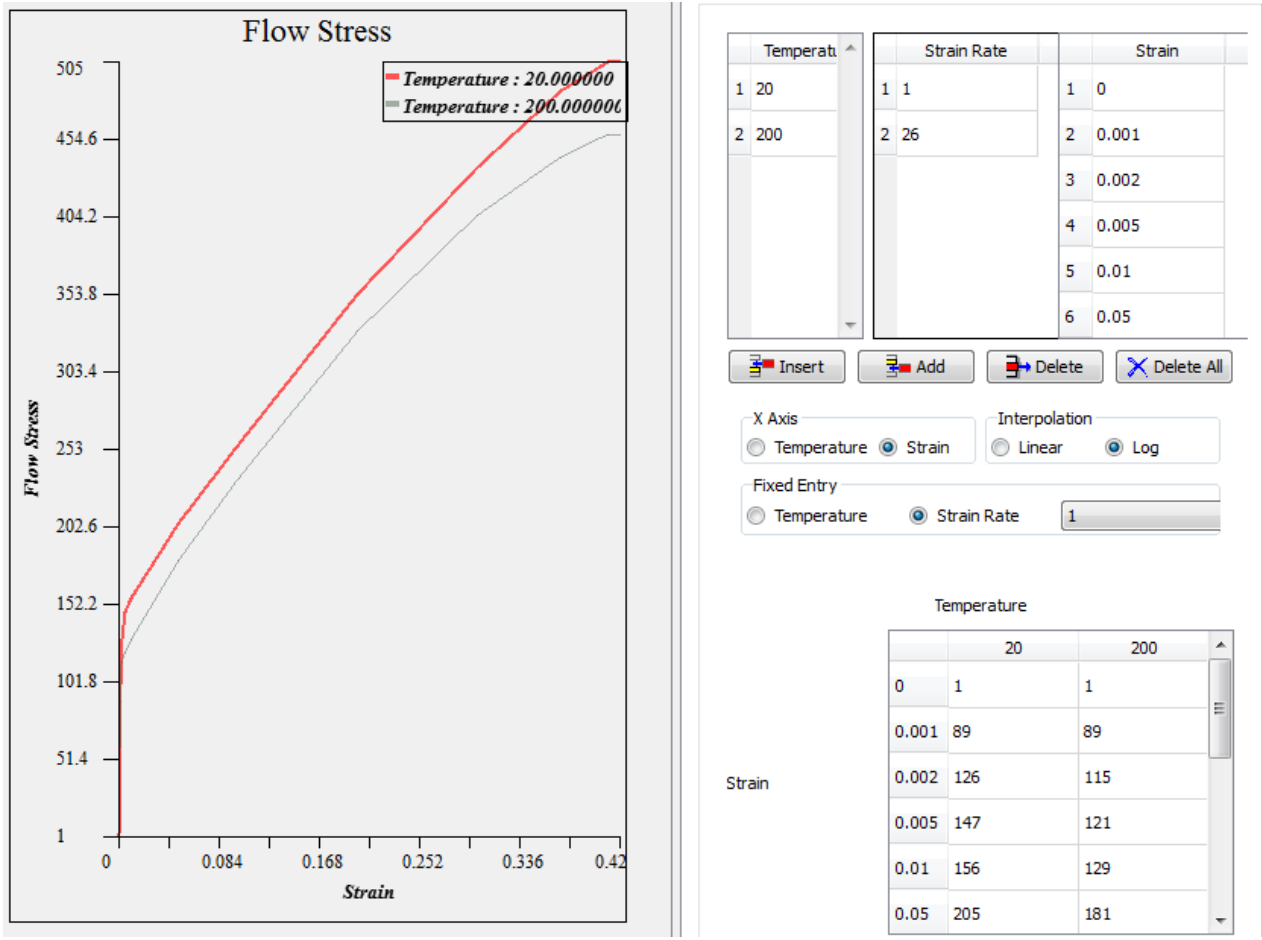

Fig. 3. Description of the material data in the DEFORM 3D

\section{Virtual tensile test}

For quick verification of entered parameters it is easiest to simulate tensile test. The specimen is fixed on side and on the other side is applied displacement with respect to the loading velocity (see Fig. 4).

\subsection{Boundary conditions}

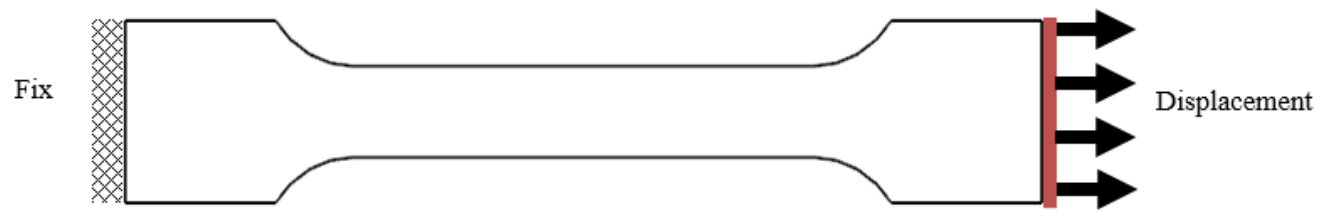

Fig. 4. Tensile test - boundary conditions

\subsection{Results and comparison}
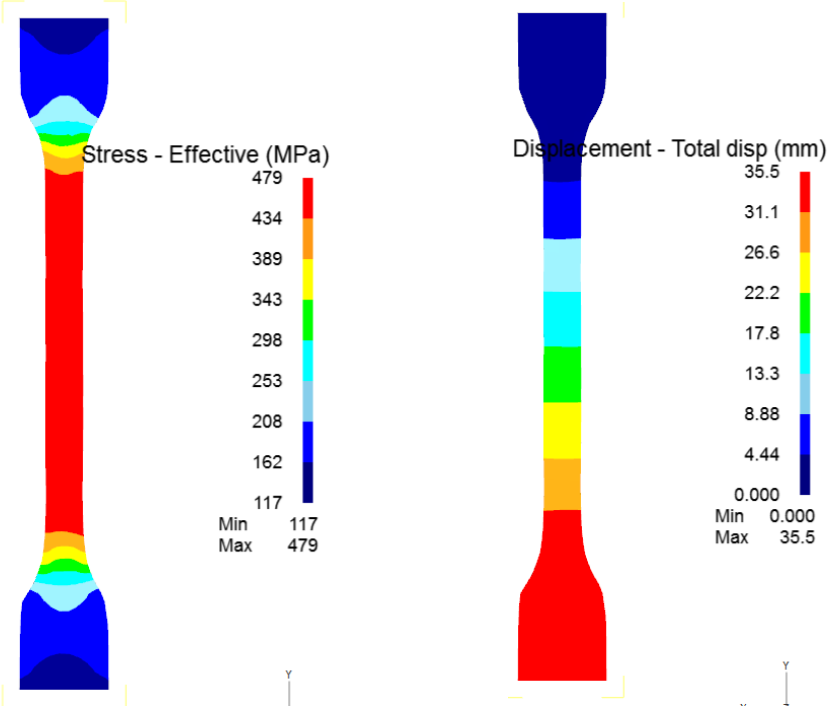

Fig. 5. Tensile test and displacement results 
The maximal stress was $475 \mathrm{MPa}$ during the initiation of the necking (Fig. 5). The ductility was $46 \%$. The real stress was $467 \mathrm{MPa}$ and ductility was $44 \%$. These results are comparable and virtual simulation was validated by the measurement.

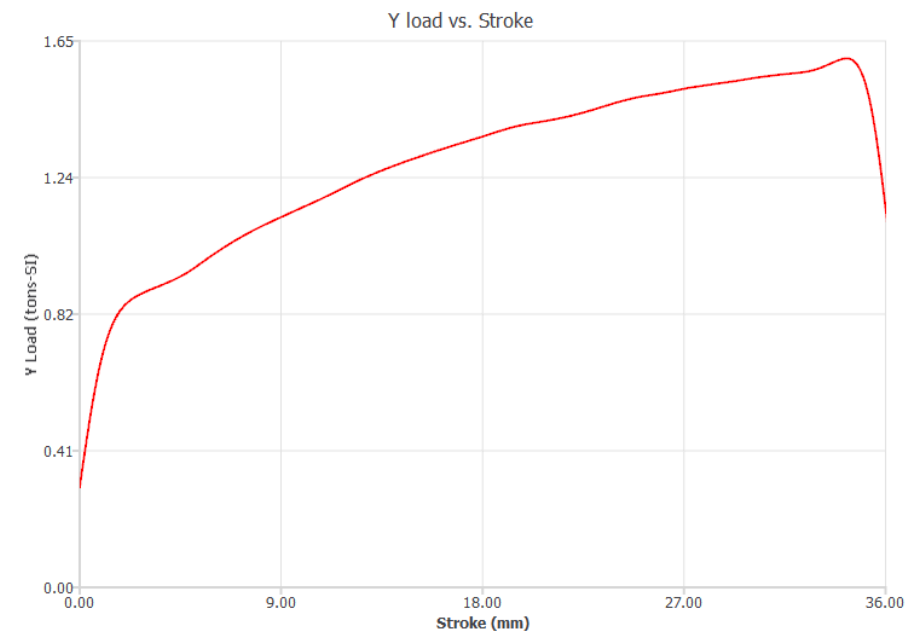

Fig. 6 Tensile test - measured force

\section{Real forming of material}

The newly obtained material data was used in the design of the tool for brass cup forming. Following figures shows the forming process entered in the Deform software and the basic cup dimensions read from the simulation. [10]
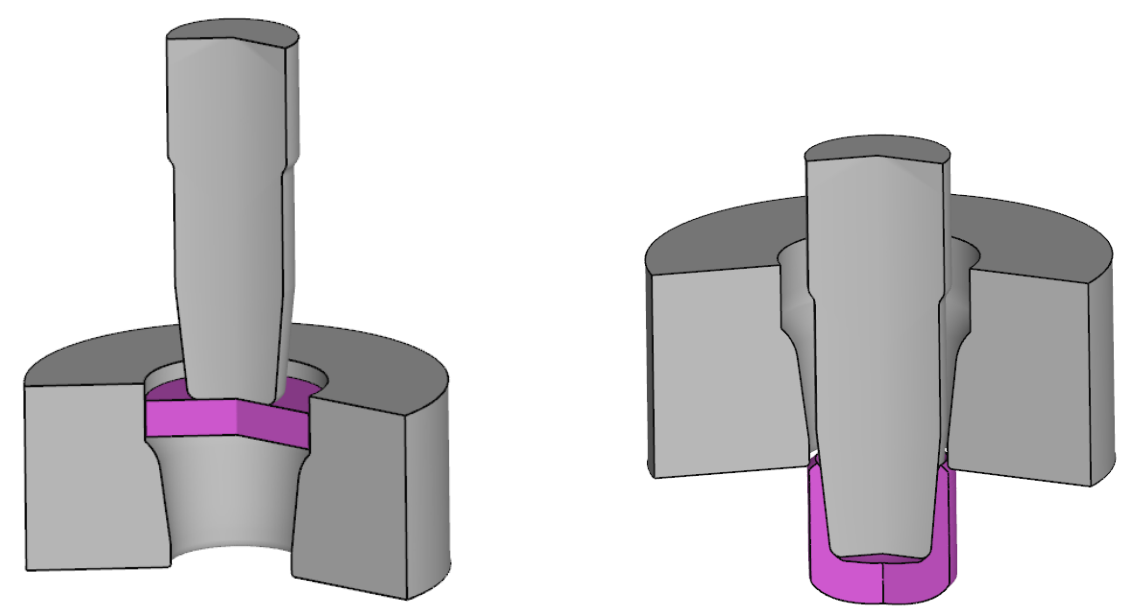

Fig. 7 Start and end of forming process

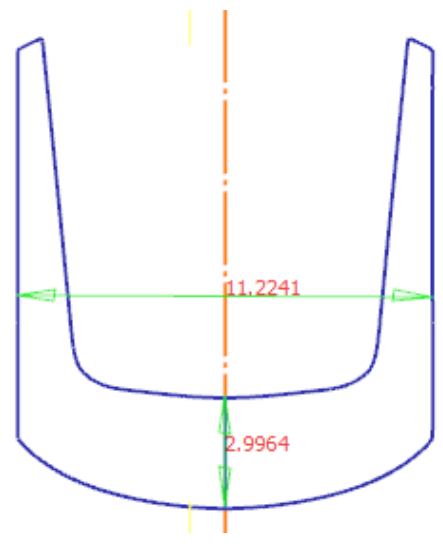

Fig. 8 Dimensions of the cup 


\begin{tabular}{|c|c|c|c|c|c|}
\hline Parameter & $\begin{array}{c}\text { Bottom } \\
\text { thickness [mm] }\end{array}$ & $\begin{array}{c}\text { Diameter } \\
{[\mathrm{mm}]}\end{array}$ & Weight $[\mathrm{g}]$ & $\begin{array}{c}\text { Centricity } \\
{[\mathrm{mm}]}\end{array}$ & $\begin{array}{c}\text { Normality } \\
{[\mathrm{mm}]}\end{array}$ \\
\hline Range of value & $2,92-3,08$ & $11,20-11,26$ & $4,80-4,90$ & 0,08 & 0,50 \\
\hline Measure 1 & 3,01 & 11,21 & 4,85 & 0,05 & 0,24 \\
\hline Measure 2 & 2,99 & 11,22 & 4,88 & 0,07 & 0,45 \\
\hline Measure 3 & 3,01 & 11,22 & 4,85 & 0,06 & 0,35 \\
\hline
\end{tabular}

Table 2. Results of real forming

By comparing the above values of the diameter and the bottom thickness, it can be concluded that the calculation corresponds to the reality and the material data are therefore correct. Other parameters from the real production cannot be compared. Accuracy is influenced by the accuracy of tool and forming press.

\section{Conclusion}

A detailed procedure for entering or editing material data for software Deform has been described. Tensile tests at various speeds and temperatures were performed on a specific CuZn30 material. After the testing was evaluated the influence of various parameters which was obtained and was decide which are important for further use. For example, it has been found that the effect of speed is not important for this brass CuZn30, but the effect of temperature is considerable.

Data were converted to real values of stress into software Deform, where it was validated by simulation of tensile test. The correct behavior of the material model was confirmed by comparison of simulated and measured values.

In the next step, the material data was applied to a real brass cup drawing calculation. Parameters achieved by virtual simulation were compared with real pressing. The value of the bottom thickness and the diameter of the cup was very similar. It has been successfully proved that the tensile test is sufficient to obtain reliable material data for brass forming. In another research, another material test could be used to obtain material data. For example bending test and compare the two approaches. Future research will be focused on mathematical description of all parameters which are necessary as inputs to the material library.

\section{Acknowledgments}

This paper was prepared thanks to the financial support provided by the Technology Agency of the Czech Republic under project no. TE01020075.

\section{References}

[1] Wessely, E; Evin, E \& T. (2012). Prediction of Deformation Properties of Steel Sheets by Numerical Simulation, Chapter 02 in DAAAM International Scientific Book 2012, pp. 019-026, B. Katalinic (Ed.), Published by DAAAM International, ISBN 978-3-901509-86-5, ISSN 1726-9687, Vienna, Austria DOI: 10.2507/daaam.scibook.2012.02019

[2] Maria, C.; Lima, O.; Sergio, R.\&B. (2000). Application of the finite element method in cold forging processes. Journal of the Brazilian Society of Mechanical Sciences. 22. 10.1590/S0100-73862000000200005.

[3] Zahalka, M. (2018). Stability of the Brass Cups Forming Process, Proceedings of the 29th DAAAM International Symposium, pp.xxxx-xxxx, B. Katalinic (Ed.), Published by DAAAM International, ISBN 978-3-902734-xx-x, ISSN 1726-9679, Vienna, Austria

[4] Colgan, M.; Monaghan, J. (2003). Deep drawing process: analysis and experiment, Journal of Materials Processing Technology, 132, pp 35-41

[5] Park, H. \& Anh, T. V. (2010). Different Methods In Analyzing Roll Forming Process Of Automotive Component, Chapter 07 in DAAAM International Scientific Book 2010, pp. 057-072, B. Katalinic (Ed.), Published by DAAAM International, ISBN 978-3-901509-74-2, ISSN 1726-9687, Vienna, Austria

[6] Pedersen, J. B. (2017). Process stabilization of cartridge case ironing, Aalborg University

[7] Raz, K.; Vaclav, K. (2014). Using of hydraulic press in production and manufacturing of large rings, Procedia Engineering, Volume 69, pp. 1064-1069, Published by Elsevier Ltd, ISSN 18777058, DOI: 10.1016/j.proeng.2014.03.091

[8] Gamboa, B. C.; Martin, F.; Sevilla, L. (2012). Friction influence on the implementation of the upper bound theorem in indentation process, B. Katalinic (Ed.), Published by DAAAM International, ISBN 978-3-901509-91-9, ISSN 2304-1382, Vienna, Austria, 2012

[9] Stehlik, A.; Vrtacek, J.; Pekovic, M. \& Jenicek, S. (2018): Measurement of Phase Transformation Temperatures Under Near-Real Conditions Using a Thermomechanical Simulator, Proceedings of the 29th International DAAAM Symposium "Intelligent Manufacturing \& Automation", 24-27th October 2018, Zadar, Croatia, Volume 29, No.1, ISSN 1726-9679, ISBN 978-3-902734-20-4

[10] Hawryluk, M. (2016). Review of selected methods of increasing the life of forging tools in hot die forging processes, Archives of Civil and Mechanical Engineering, 16(4), pp. 845-866 